\title{
Synthesis, Crystallographic Characterization and Density Functional Study of Novel Spoke-Molecular Tetravent ethyltriphenylphosphorous Dibromide
}

\author{
A. M. MKADMH ${ }^{1 *}$, A. M. ABU-SHANAB ${ }^{1}$, R.Y. MORJAN ${ }^{2}$, Z. SAFI ${ }^{3}$, \\ ROBIN G. PRITCHARD ${ }^{4}$ and JOHN M. GARDINER ${ }^{5}$
}

\begin{abstract}
${ }^{1}$ Chemistry Department, College of Applied Science, Al-Aqsa University, Gaza- Palestine
${ }^{2}$ Chemistry Department, College of Science, Islamic University of Gaza, Gaza-Palestine

${ }^{3}$ Chemistry Department, College of Applied Science, Al-Azhar University, Gaza- Palestine

${ }^{4}$ School of Chemistry, The University of Manchester, Manchester, M13 9PL, UK

${ }^{5}$ Manchester Institute of Biotechnology, School of Chemistry, Faculty of EPS,

The University of Manchester, Manchester M1 7DN, UK

am.almagadma@alaqsa.edu.ps
\end{abstract}

Received 24 April 2016 / Accepted 11 May 2016

\begin{abstract}
A novel molecular tetravalent ethyltriphenylphosphorous dibromide $\left(\left(\mathrm{C}_{6} \mathrm{H}_{5}\right)_{3} \mathrm{PCH}_{2} \mathrm{Br}_{2}\right)$ has been synthesized in toluene and has been characterized by single crystal x-ray crystallography. Theoretical studies have been conducted utilizing DFT(B3LYP/6-311+G(d,p) level of theory both in gas phase and solution using diverse solvents. Potential surface energy calculations revealed the existence of the tetravalent diionic form as a global minimum except in dimethylsulfoxide where our adduct is more stable. Calculations showed that the $\mathrm{Br}-\mathrm{Br}$ bond distance is in quadratic variation with the medium dielectric constant. The unusual $\mathrm{Br}-\mathrm{Br}$ lengthen is reasonably rationalized in terms of charge transfer of electron density from the $\pi$ clouds in phenyl moieties to the $\sigma^{*}$ of the dibromine entity. The average harmonic oscillator index of aromaticity of the complex are found suffering a deviation from unity.
\end{abstract}

Keywords: Organophosphorous, X-ray, DFT, AHOMA, Hardness

\section{Introduction}

Organophosphorous halogen compounds (OPHCs) have distracted chemists intentions for decades due to its important role in organic chemistry as synthetic reagents, bond cleavage reagents and displacement ones. A vast number of OPHCs of the formula $R_{3} P X_{2}$ and $R_{3} P E X_{2}$ $\left[R=\right.$ alkyl, aryl; $\left.E=P, S e, S, A s, S b, B i ; X_{2}=C l_{2}, B r_{2}, I_{2}, I C l, I B r\right]$ have been prepared ${ }^{1-9}$. These compounds in the solid state are found crucially dependent on the nature of the solvent used in the synthesis process ${ }^{10}$. Compounds of the formula $R_{3} P X_{2} ;[R=P h, M e, n$-octyl, $n$-hexyl, $n$-butyl $X=C l, B r, I]$ and compounds of the formula ${ }^{11-13} \mathrm{Ph}_{3} P X Y ;\left(X Y=\mathrm{Br}_{2}, I_{2}, I B r\right)$ that have been prepared in acetonitrile, dichloromethane or in nitrobenzene ${ }^{14-16}$ are ionic with tetrahedral geometry and the correct form will be $\left[R_{3} P X\right]^{+} Y$.

Extensive studies on the compounds of the formula $R_{3} E X_{2}\left(R_{3}=P h_{3}, P h M e_{2}, M_{3} ; E=P\right.$, As; $\mathrm{X}_{2}=\mathrm{Br}_{2}{ }^{17}, \mathrm{I}_{2}{ }^{17,18} \mathrm{IBr}^{16}$ that isolated from diethyl ether solution which is relatively weak 
polar solution leads to the formation of another geometrical structure of these compounds which is a four co-ordinate molecular spoke structure of the formula $R_{3} E-X-X$ in the solid state as it has been proved by X-ray crystallographic studies. In $\mathrm{CDCl}_{3}$ solution, which is a highly polar solvent, all the compounds ionise completely to form $\left[R_{3} P X\right]^{+} X$. Further series of linear spoke molecular structure of stoichiometry ${ }^{19} R_{3} P_{2} \quad\left[R_{3}=\left(o-M_{e} O_{6} H_{4}\right)_{3}\right.$, $\left(\mathrm{o}-\mathrm{MeOC}_{6} \mathrm{H}_{4}\right)_{2} \mathrm{Ph},\left(\mathrm{o}-\mathrm{MeOC}_{6} \mathrm{H}_{4}\right) \mathrm{Ph}_{2},\left(p-\mathrm{FC}_{6} \mathrm{H}_{4}\right)_{2} \mathrm{Ph},\left(\mathrm{p}-\mathrm{FC}_{6} \mathrm{H}_{4}\right) \mathrm{Ph}_{2},\left(p-\mathrm{CH}_{2}=\mathrm{CHC}_{6} \mathrm{H}_{4}\right) \mathrm{Ph}_{2}$, $\left(\mathrm{CH}_{2}=\mathrm{CHCH}_{2}\right)_{2} \mathrm{Ph},\left(\mathrm{C}_{6} \mathrm{H}_{11}\right) \mathrm{Ph}_{2},\left(\mathrm{PhCH}_{2} \mathrm{CH}_{2}\right)_{3}$ or $\left(\mathrm{Me}_{2} \mathrm{~N}\right)_{3}$ ] have been synthesized in diethyl ether. It is found that all of these compounds ionize in the highly polar $\mathrm{CDCl}_{3}$ solution. Nevertheless, the compounds $\left(\mathrm{Me}_{2} \mathrm{~N}_{3} \mathrm{PI}_{2}\right.$ and $\left(\mathrm{CH}_{2}=\mathrm{CHCH}_{2}\right)_{2} \mathrm{PhPI}_{2}$ proved to be ionic in the solid state which is in contradict to the four co-ordinate molecular geometry of the compounds $R_{3} P I_{2}$ that have been already mentioned.

Molecular trigonal bipyramidal compounds were identified as in the case ${ }^{20}$ of $R_{3} P F_{2}(R$ $=P h, M e, E t$, or $n B u), P h_{3} A s B r_{2}{ }^{19} . R_{3} P C l_{2}\left[R=\left(C_{6} F_{5}\right)_{3}\right.$ or $\left.\left(C_{6} F_{5}\right) P h_{2}\right]$. Such compounds having molecular five coordinate trigonal bipyramidal geometries were prepared in diethyl ether and crystallography identified by Godfrey and co-workers ${ }^{14} \cdot\left(C_{6} F_{5}\right)_{3} P C l_{2}$ exhibited a trigonal-bipyramidal geometry, while $\left(C_{6} F_{5}\right) \mathrm{Ph}_{2} \mathrm{PCl}_{2}$ showd a significant distortion due to asymmetry of the equatorial groups around $P$ atom. It is found that the molecular trigonal bipyramidal pentavalent molecular geometry of $\mathrm{Ph}_{3} \mathrm{PCl}_{2}$ dominant in solvents of low polarity, but converts into an ionic form in highly polar solvents ${ }^{14}$.

In addition to the influence of the nature of the solvent used in synthesis the nature of the $R$ group bound to the $E$ metal has a fundamental effect on the structure of the dihalogen compounds. This impact could be touched easily if $R$ is varied while both of $E$ and $X_{2}$ are maintained unchanged in the dihalogen compounds. For example ${ }^{19,21}, R_{3} A s B r_{2}$ compounds adopted the trigonal-bipyramidal structure when $R=P h$, whereas the structure of the $M e$ isomer is the molecular linear spoke charge transfer of tetrahedral geometry of the formula ${ }^{19}$ $M e_{3} A s-B r-B r$. It was accounted that the acidity of the $E$ group is responsible for this behaviour. A pentavalent molecular geometry is more likely with increasing the acidity of $E R_{3}$, i.e. the probability of preparing the trigonal-bipyramidal structure is enhanced in the presence of a suitably acidic tertiary phosphine. A similar situation is observed for the dichloro adducts ${ }^{14,21-23}, \mathrm{R}_{3} \mathrm{PCl}_{2}$ being ionic with the formula $\left[\mathrm{R}_{3} \mathrm{PCl}\right]^{+} \mathrm{Cl}$ when the alkyl group is methyl, $n$-propyl or isopropyl, whereas the trigonal bipyramidal geometrical structures are adopted when $\left[R_{3}=\left(C_{6} F_{5}\right)_{3}\right.$ or $\left[P h_{2}\left(C_{6} F_{5}\right)\right]^{24}$.

The nature of the substituents not only, significantly, affect the geometrical structure of $O P H C$, but also affect each of the $E-E^{\prime}, E-X, E^{\prime}-X$ and $X-X$ bond lengths ${ }^{24}$. For example, the (I-I) bond length in $P h_{3} P-I-I$ is $316.1 \mathrm{pm}^{17}$ while the same bond in $P h M e_{2} P-I-I$ is $340.9 \mathrm{pm}^{25}$ and it is $333.2 \mathrm{pm}$ in case ${ }^{26}$ of $t-\mathrm{Bu}_{3} \mathrm{PI}_{2}$. Another example, the $\mathrm{P}-\mathrm{Se}, \mathrm{Se}-\mathrm{Br} r_{1}$ and $\mathrm{Se}-\mathrm{Br}_{2}$ bond lengths in $\left(C_{6} \mathrm{H}_{11}\right)_{3} \mathrm{PseBr}_{2}$ are $227.1 \mathrm{pm}, 256.8 \mathrm{pm}$ and $256.6 \mathrm{pm}$ respectively, whereas the $P$ $\mathrm{Se}, \mathrm{Se}-\mathrm{Br}_{1}, \mathrm{SeBr}_{2}$ bond lengths in $\left(\mathrm{Me}_{2} \mathrm{~N}\right)_{3} \mathrm{PseBr}_{2}$ are $226.2 \mathrm{pm}, 260.2 \mathrm{pm}$ and $254.4 \mathrm{pm}$ respectively ${ }^{1}$.

Adducts of the formulas $\mathrm{Ph}_{3} \mathrm{PRBr}$; [R=Ph, Me, Et or $\left.\mathrm{C}_{5} \mathrm{H}_{9}\right]$ and $\mathrm{Ph}_{3} \mathrm{PRCl}$; $\mathrm{R}=\mathrm{Bu}$ were recently isolated and crystallography identified by Burgess et al. However ${ }^{27}$, compounds of the formula $\mathrm{ArPRX}_{2}$ have not received that remarkable attention. Compounds of the formula ${ }^{28}$ $\left[\mathrm{Ph}_{3} \mathrm{PCH}_{2} \mathrm{Br}\right]^{+} \mathrm{Br}^{-}$and $\left[\mathrm{Ph}_{3} \mathrm{PCH}_{2} \mathrm{I}\right]^{+} \mathrm{I}^{-}$as a di-ionic ${ }^{29}$ molecular entities have been successfully prepared. Bromomethyltriphenylphosphonium bromide plays an import roll in organic synthesis. It is an essential reagent for carbon-carbon bond formation in Wittig reaction ${ }^{30}$. It is also used as starting material in synthesis of benzyldiphenylphosphine oxide which in turn and with other reagents, can be used for alkenes synthesis ${ }^{31}$. 
In this study the possibility of preparing compounds of the formula $\mathrm{Ar}_{3} \mathrm{PRX}_{2} ; \mathrm{R}=\mathrm{CH}_{2}$, $\mathrm{X}_{2}=\mathrm{Cl}_{2}, \mathrm{Br}_{2}$ will be examined and then will be theoretically investigated employing the density functional theory to shed the light on their geometries and electronic properties.

\section{Experimental}

The synthesis of the title compound has been accomplished in a similar manner to the one has been reported in the literature ${ }^{31}$, prepared by the reaction of $10 \mathrm{mmol}(2.62 \mathrm{~g})$ triphenylphosphine and $10 \mathrm{mmol}(1.74 \mathrm{~g})$ dibromomethane under reflux in toluene and a white needle crystals were separated.

$\mathrm{X}$-ray single crystal data were collected at $230 \mathrm{~K}$ using graphite monochromated Mo-K $\alpha\left(\lambda=0.7107 \mathrm{~A}^{\circ}\right)$ radiation on a Bruker SMART APEX CCD diffractometer. Data reduction was carried out using SAINT ${ }^{32}$ and the structure was solved using SHELXS-97 ${ }^{33}$ and showed that there are two molecules in the asymmetric unit. Full matrix refinement on $F^{2}$ was performed with SHELXL- $97^{33}$ and all calculations were carried out using the SHELXTL package ${ }^{33}$. The non- $\mathrm{H}$ atoms were refined anisotropically and $\mathrm{H}$ atoms were included in calculated positions, except for those bonded to $\mathrm{N}$, which were found by Difference Fourier Methods and refined isotropically. It was necessary to collect the data at 230 , since flash freezing to $100 \mathrm{~K}$ caused the crystal to break up. The crystal data are summarized in Table 1.

Table 1. Crystal data and structure refinement of bromomethyltriphenylphosphonium bromide

\begin{tabular}{|c|c|c|}
\hline \multicolumn{2}{|l|}{ Parameter } & Synthesized compoud \\
\hline \multicolumn{2}{|l|}{ Empirical formula } & $\mathrm{C}_{19} \mathrm{H}_{17} \mathrm{Br}_{2} \mathrm{P}$ \\
\hline \multicolumn{2}{|l|}{ Formula weight } & 436.12 \\
\hline \multicolumn{2}{|l|}{ Crystal color } & Colorless \\
\hline \multicolumn{2}{|l|}{ Crystal size, $\mathrm{mm}^{3}$} & $0.15 \times 0.12 \times 0.05$ \\
\hline \multicolumn{2}{|l|}{ Crystal system } & Monoclinic \\
\hline \multirow[t]{3}{*}{ Space group } & & $\mathrm{P} 2(1) / \mathrm{n}$ \\
\hline & $\mathrm{a}(\hat{\AA})$ & $10.3077(2)$ \\
\hline & $b(\AA)$ & $14.0568(3)$ \\
\hline Unit & $c(\AA)$ & $12.4893(2)$ \\
\hline \multirow[t]{3}{*}{ cell dimensions } & $\alpha, \operatorname{deg}$ & 90 \\
\hline & $\beta$, deg & $105.152(1)$ \\
\hline & $\gamma, \operatorname{deg}$ & 90 \\
\hline \multicolumn{2}{|l|}{$\mathrm{V}\left(\AA^{3}\right)$} & $1746.71(6)$ \\
\hline \multicolumn{2}{|l|}{$\mathrm{Z}$} & 4 \\
\hline \multicolumn{2}{|l|}{$\mathrm{D}, \mathrm{g} \mathrm{cm}^{-3}$} & 1.404 \\
\hline \multicolumn{2}{|l|}{$\mathrm{F}(000)$} & 576 \\
\hline \multicolumn{2}{|l|}{$\mu \mathrm{MoK} \alpha, \mathrm{mm}^{-1}$} & 4.73 \\
\hline \multicolumn{2}{|l|}{$\mathrm{T}, \mathrm{K}$} & 150 \\
\hline \multicolumn{2}{|c|}{$\lambda, \AA$} & 0.71073 \\
\hline \multicolumn{2}{|c|}{ Absorption coefficient, $\mathrm{mm}^{-1}$} & 0.104 \\
\hline \multicolumn{2}{|c|}{ Absorption correction: multi-scan } & 3431 reflections with \\
\hline \multicolumn{2}{|c|}{ Range of $h, 1, k$} & $-15 / 16,-14 / 14,13 / 12$ \\
\hline \multicolumn{2}{|l|}{$\theta \min / \max (\mathrm{deg})$} & 1.65 to 28.28 \\
\hline \multicolumn{2}{|c|}{$\mathrm{R}(\mathrm{int})$} & 0.044 \\
\hline \multicolumn{2}{|c|}{ Completeness to $\theta=25.00$} & $100.0 \%$ \\
\hline
\end{tabular}




\begin{tabular}{ll}
\hline reflections collected/unique/ & $10923 / 3077[\mathrm{R}(\mathrm{int})=0.0562]$ \\
Data/restraints/parameters & $4002 / 1.07 / 268$ \\
$\mathrm{GOF}$ on $\mathrm{F}^{2}$ & 0.946 \\
Final $R$ indices $[\mathrm{I}>2 \sigma(\mathrm{I})] \mathrm{R}_{1}, \mathrm{wR}_{2}$ & $0.028,0.065$ \\
$R$ indices (all data) $\mathrm{R}_{1}, \mathrm{wR}_{2}$ & $0.0675,0.1040$ \\
$\Delta \rho_{\min }, \Delta \rho_{\max }$ & $-0.58 \mathrm{e} \AA^{-3}, 0.48 \mathrm{e}^{-3}$ \\
Max. and min. transmission & 0.9794 and 0.9693 \\
Extinction coefficient & $0.0211(19)$ \\
Refinement method & Full-matrix least-squares on $\mathrm{F}^{\wedge} 2$ \\
\hline
\end{tabular}

\section{Computational details}

The title compounds was initially fully optimized in the gas phase with no geometrical constrains at the density functional of Becke three-parameters hybrid functional of Lee, Yang and Parr ${ }^{34,35}$ (DFT/B3LYP) in combination with the sophisticated 6-311+G(d,p) basis set in which diffused functions have been added for all atoms while polarized ones have been added to the heavy ones. Extra different basis sets were employed on phosphorous and bromine moieties in attempt to assign the most convenient basis set for each of $\mathrm{P}$ and $\mathrm{Br}$ to be used in this study. It is found that the sophisticated standard Dunning's correlation consistent quadruple-zeta augmented basis set with diffuse functions $^{36}$, aug-ccpV $(\mathrm{Q}+\mathrm{d}) \mathrm{Z}$ could be satisfactorily employed for the phosphorous moieties to account for any diffusion of the charge densities. Previous studies conducted by Martin et al. and others ${ }^{37-39}$ confirmed the necessity of employing such tight diffused functions in case of elements of the third period in periodic table. The ground state nature of each compound is examined by analytical vibrational frequency calculations conducted using second-derivative computations at the same level of theory. Energies, energies of frontier orbitals, aromaticity indices, global softnesses and global hardnesses were calculated at the single point energy calculations with the DFT(B3LYP)/6-311++G(3d,3p) level of theories. The optimized gaseous wavefunctions were then taken as the input for calculations in solution by using the Conductor-Like Polarized Continuum Model (CPCM) of Barone ${ }^{40}$ and Cossi $^{41}$ which is based on the polarizable Continuum Model (PCM) of Tomassi and co-workers ${ }^{42-46}$ at B3LYP/6-311++G(3d,3p)// B3LYB/6$311+\mathrm{G}(\mathrm{d}, \mathrm{p})$ level of theory in dimethyl sulfoxide in attempt to account for the unusual length of the $\mathrm{Br}-\mathrm{Br}$ bond distance predicted by the experimental single $\mathrm{X}$-ray crystallography. Extrabasis sets were used for the phosphorous moieties.

All calculations were performed with the Gaussian 09 package ${ }^{47}$. Gauss View ${ }^{48}$ and Chemcraft ${ }^{49}$ programs were used for visualization of structures while ${ }^{50}$ Mercury 3 was used for visualization and analysis of crystal structure.

\section{Results and Discussion}

\section{Basis set}

Different bases functions were used for $\mathrm{P}$ and $\mathrm{Br}$ atoms while $\mathrm{C}$ and $\mathrm{H}$ atoms were optimized at the $6-311+\mathrm{g}(\mathrm{d}, \mathrm{p})$ basis functions. Table 2 presents the bases functions employed at the gas phase and liquid state for the $\mathrm{P}$ and $\mathrm{Br}$ moieties at seven different jobs, the linear correlation factor of plotting the calculated geometrical ( bond lengthy and bond angles) parameters versus the corresponding observed $\mathrm{x}$ - ray ones and the predicted $\mathrm{Br}-\mathrm{Br}$ bond lengths in $\mathrm{pm}$.

The best correlation factors in cases of bond distances are obtained with jobs 2 and 4 $\left(R^{2}=0.907\right.$ and 0.909$)$ respectively where job 4 showed better representation of the distance 
parameters with 0.002 correlation factor increment. Nevertheless, job 3 proved to be more reliable in terms of the bending angle parameters due to 0.009 correlation factor increment. One would came to the result that the basis sets employed in the calculation conducted in job 3 would give better representation of predicting geometrical parameters. As a result of that, the basis sets $6-311+\mathrm{g}(\mathrm{d}, \mathrm{p})$ would be used for the entire molecule while the quadruple-zeta augmented basis set with diffuse function (aug-cc-pvqz+d) could be taken as an excellent one for calculation of $\mathrm{P}$ atom in the study. The validity of this basis set choice is strengthened by the calculation in solution where an excellent correlation between the calculated and observed parameters were obtained; 0.999 and 0.993 for the bond distances and bending angles respectively as it is clear from Figures 1a and $1 \mathrm{~b}$. It would be fair enough to recommend such basis set combinations in theoretical investigation of family of such compounds. Bond distances and bending angles predicted at the aforementioned bases sets at the specified level of theories are recorded in Table 3 and Table 4 respectively.

Table 2. The basis functions used for $\mathrm{Br}$ and $\mathrm{P}$ moieties in $\left(\mathrm{C}_{6} \mathrm{H}_{5}\right)_{3} \mathrm{PCH}_{2} \mathrm{Br}_{2}$, the regression and the estimated $\mathrm{Br}-\mathrm{Br}$ bond distance in each job

\begin{tabular}{|c|c|c|c|c|c|c|}
\hline \multirow{6}{*}{ Gas phase } & Job & atom & Basis function & $\begin{array}{c}\mathrm{R}^{2} /(\text { Bond } \\
\text { length) }\end{array}$ & $\begin{array}{l}\mathrm{R}^{2} /(\text { Bending } \\
\text { angle) }\end{array}$ & $\mathrm{d}_{\mathrm{Br}-\mathrm{Br}} / \mathrm{pm}$ \\
\hline & 1 & $\begin{array}{l}\mathrm{P} \\
\mathrm{Br}\end{array}$ & $\begin{array}{l}\text { Aug-cc- } \\
\text { pvqz+d }\end{array}$ & 0.903 & 0.991 & 270.8 \\
\hline & 2 & $\begin{array}{c}\mathrm{P} \\
\mathrm{Br}\end{array}$ & $\begin{array}{l}\text { cc-pvqz+d } \\
6-311 \mathrm{~g}(\mathrm{~d}, \mathrm{p})\end{array}$ & 0.899 & 0.979 & 271.4 \\
\hline & 3 & $\begin{array}{l}\mathrm{P} \\
\mathrm{Br}\end{array}$ & $\begin{array}{c}\text { Aug-cc-pvqz+d } \\
6-311+g(d, p)\end{array}$ & 0.907 & 0.989 & 273.1 \\
\hline & 4 & $\begin{array}{l}\mathrm{P} \\
\mathrm{Br}\end{array}$ & $\begin{array}{l}\text { Aug-cc-pvqz+d } \\
\text { Lanl2dz }\end{array}$ & 0.909 & 0.980 & 272.6 \\
\hline & 5 & $\begin{array}{l}\mathrm{P} \\
\mathrm{Br}\end{array}$ & $6-311+\mathrm{g}(\mathrm{d}, \mathrm{p})$ & 0.893 & 0.977 & 270.9 \\
\hline \multirow{2}{*}{ Solution } & 6 & $\begin{array}{c}\mathrm{P} \\
\mathrm{Br}\end{array}$ & $6-311+g(d, p)$ & 0.999 & 0.984 & 351.7 \\
\hline & 7 & $\begin{array}{l}\mathrm{P} \\
\mathrm{Br}\end{array}$ & $\begin{array}{c}\text { Aug-cc-pvqz+d } \\
6-311+g(d, p)\end{array}$ & 0.999 & 0.993 & 352.3 \\
\hline
\end{tabular}

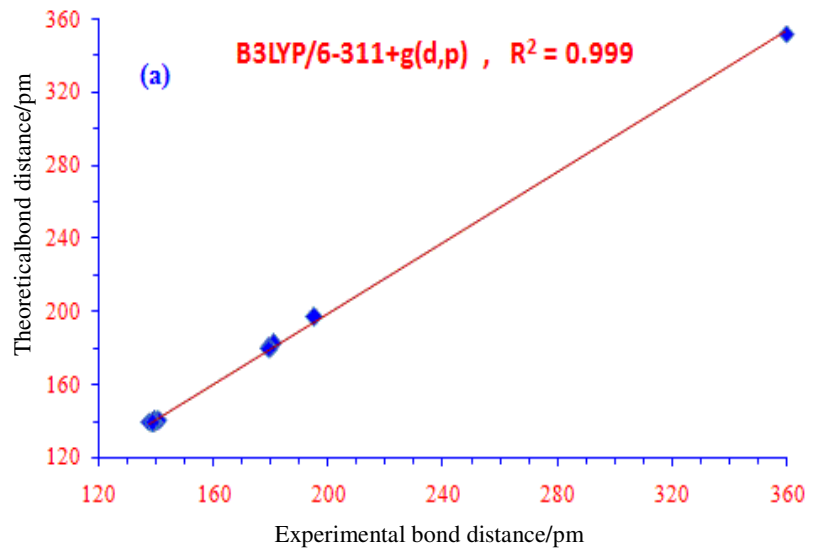




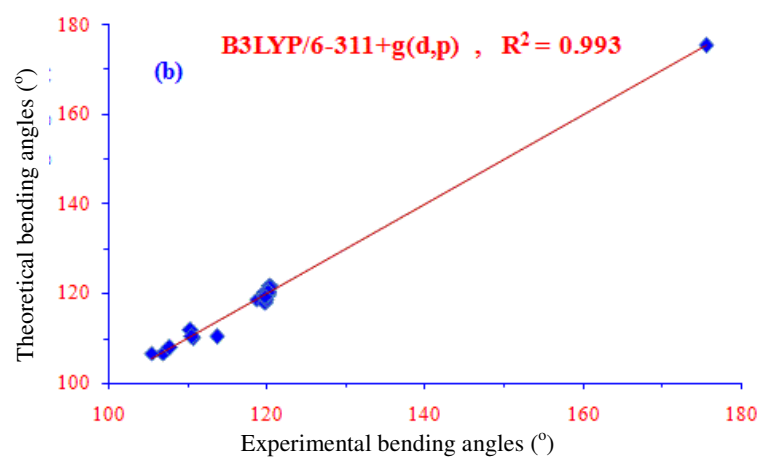

Figure 1. Correlation graphs of the calculated DFT geometrical parameters and the experimental ones; (a) bond distances and (b) bending angles of the title compound

\section{Molecular structure}

Preparation of the novel product bromomethyltriphenylphosphonium bromide $\mathbf{3}$ was effected through a condensation reaction of triphenylphosphine $\mathbf{1}$ and dibromomethane $\mathbf{2}$ under reflux in toluene (Scheme 1). The formation of $\mathbf{3}$ was confirmed by x-ray crystallography.

Table 3. Experimental and theoretical bond distances of $\left(\mathrm{C}_{6} \mathrm{H}_{5}\right)_{3} \mathrm{PCH}_{2} \mathrm{Br}_{2}$

\begin{tabular}{ccccccccc}
\hline $\begin{array}{c}\text { Bond } \\
\text { Distance }\end{array}$ & X-Ray & Job (1) & Job (2) & Job (3) & Job (4) & Job (5) & Job (6) & Job (7) \\
\hline C1-P1 & $1.805(2)$ & 177.3 & 177 & 177.3 & 177.2 & 178.4 & 184.1 & 182.6 \\
C1-Br1 & $1.951(2)$ & 216.9 & 219.1 & 217.2 & 216.5 & 219.5 & 196.9 & 197 \\
C2-C7 & $1.388(3)$ & 140.2 & 140 & 140 & 140.2 & 140 & 140.1 & 140.2 \\
C2-C3 & $1.402(3)$ & 140 & 140.1 & 139.1 & 140.4 & 140 & 140.3 & 140.3 \\
C2-P1 & $1.794(2)$ & 180.4 & 180.4 & 180.5 & 180.1 & 181.7 & 181 & 179.6 \\
C3-C4 & $1.383(4)$ & 139.2 & 139 & 139.1 & 139.2 & 139.1 & 139.1 & 139.1 \\
C4-C5 & $1.383(4)$ & 139.3 & 139.4 & 139.4 & 139.7 & 139.3 & 139.5 & 139.5 \\
C5-C6 & $1.383(4)$ & 139.4 & 139.2 & 139.3 & 139.5 & 139.3 & 139.3 & 139.4 \\
C6-C7 & $1.392(3)$ & 139 & 139.2 & 139.3 & 139.5 & 139.2 & 139.3 & 139.3 \\
C8-C9 & $1.388(3)$ & 140 & 140 & 140 & 140.3 & 139.9 & 140.1 & 140.2 \\
C8-C13 & $1.392(3)$ & 140.3 & 140.3 & 140.4 & 140.4 & 140.3 & 140.4 & 140.5 \\
C8-P1 & $1.790(2)$ & 182.1 & 182.1 & 182 & 181.8 & 183.3 & 181.6 & 180.3 \\
C9-C10 & $1.386(4)$ & 139.3 & 139.3 & 139.5 & 139.4 & 139.4 & 139.3 & 139.2 \\
C10-C11 & $1.378(4)$ & 139.2 & 139.2 & 139.2 & 139.6 & 139.2 & 139.4 & 139.4 \\
C11-C12 & $1.375(4)$ & 139.5 & 139.5 & 139.6 & 139.7 & 139.5 & 139.5 & 139.5 \\
C12-C13 & $1.389(4)$ & 139 & 139 & 139 & 139.4 & 139 & 139.2 & 139.1 \\
C14-C15 & $1.391(3)$ & 140 & 140.2 & 140.3 & 140.4 & 140.1 & 140.1 & 140.2 \\
C14-C19 & $1.407(3)$ & 140.5 & 140.5 & 140.4 & 140.8 & 140.4 & 140.4 & 140.5 \\
C14-P1 & $1.792(2)$ & 180.8 & 180.8 & 180.8 & 180.6 & 182 & 181.4 & 180.1 \\
C15-C16 & $1.392(3)$ & 139.3 & 139.3 & 139.3 & 139.5 & 139.3 & 139.5 & 139.3 \\
C16-C17 & $1.389(4)$ & 139.3 & 139.3 & 139.4 & 139.5 & 139.3 & 139.3 & 139.3 \\
C17-C18 & $1.384(3)$ & 139.3 & 139.4 & 139.4 & 139.7 & 139.4 & 139.3 & 139.5 \\
C18-C19 & $1.385(3)$ & 139.1 & 139.1 & 139.2 & 139.3 & 139.1 & 139.3 & 139.1 \\
Br-Br & $359.7(3)$ & 270.8 & 271.4 & 273.1 & 272.6 & 270.9 & 351.7 & 352.3 \\
R^2 & & 0.903 & 0.899 & 0.907 & 0.909 & 0.893 & 0.999 & 0.999 \\
\hline
\end{tabular}


Table 4. Experimental and theoretical bending angles of $\left(\mathrm{C}_{6} \mathrm{H}_{5}\right)_{3} \mathrm{PCH}_{2} \mathrm{Br}_{2}$

\begin{tabular}{|c|c|c|c|c|c|c|c|c|}
\hline Bond Angle & X-Ray & Job (1) & Job (2) & Job (3) & Job (4) & Job (5) & Job (6) & Job (7) \\
\hline P1-C1-Br1 & $110.32(12)$ & 113.7 & 113.4 & 110.5 & 110.3 & 114.4 & 114.6 & 113.6 \\
\hline C7-C2-C3 & 119.7(2) & 19.8 & 119.8 & & 119.9 & 120 & 20.1 & 119.9 \\
\hline C7-C2-P1 & $121.69(17)$ & 120.2 & 120.2 & 120.3 & 120.6 & 120.1 & 120.1 & 120.3 \\
\hline C3-C2-P1 & $118.52(18)$ & 120 & 120 & 120 & 119.5 & 120 & 119.7 & 118.7 \\
\hline $\mathrm{C} 4-\mathrm{C} 3-\mathrm{C} 2$ & $119.6(2)$ & 120 & 119.9 & 119.9 & 119.9 & 119.8 & 119.7 & 119.8 \\
\hline $\mathrm{C} 5-\mathrm{C} 4-\mathrm{C} 3$ & 120.7 & 120.1 & 120.2 & 20.2 & 120.1 & 120.2 & 20.2 & 120.1 \\
\hline 5-C6 & 119.8 & 120.1 & 120.1 & 120.1 & 120.2 & 120.1 & 20.2 & 120.2 \\
\hline & 120.3 & 120.2 & 120 & 120 & 120 & 20.1 & 20.2 & 120.1 \\
\hline C2-C7-C6 & 119.9( & 119.9 & 120 & 120 & 119.9 & & 19.7 & 119.8 \\
\hline C9-C8-C13 & $120.1(2)$ & 19.3 & 119.3 & 119.4 & 9.5 & & 120.1 & 119.8 \\
\hline C9-C8-P1 & $121.82(1$ & 121 & 121 & 121.8 & 1.4 & 1.7 & 119.7 & 120.4 \\
\hline C13-C8-P1 & 117.84( & .9 & 118.9 & 118.8 & 119.1 & 118.8 & 120.2 & 119.8 \\
\hline $\mathrm{C} 10$ & 1 & 20.1 & 1 & 120.1 & 120.1 & & 9.7 & 119.9 \\
\hline C11- & & 120.2 & 120 & & 120.2 & 0.3 & 0.2 & 120.2 \\
\hline & 120. & & & 120 & 120 & & 120.2 & 120.1 \\
\hline C11-C12-C13 & 120.1 & 120.1 & 120.1 & 120.1 & 120 & 0.1 & 120.2 & 120.2 \\
\hline C12-C13-C8 & 119.6 & & & 120.3 & & & 9.7 & 119.8 \\
\hline 14-C19 & 120.3 & 120.3 & 119.7 & 12 & 119.8 & 9.9 & 120 & 119.8 \\
\hline & 121.22 & & & 120.5 & 119.7 & 20.9 & 120.1 & 120.3 \\
\hline & & & & & 120.5 & & & 119.9 \\
\hline $\mathrm{C} 16$ & 1 & $11 \mathrm{c}$ & & 0.1 & 20 & & 9.8 & 119.9 \\
\hline & & & & & & & & 120.2 \\
\hline C18-C17-C16 & $120.4(2)$ & & & & & & 0.1 & 120.1 \\
\hline C17-C18-C19 & $120.2(2)$ & 120.1 & 120 & 120.4 & 120.4 & & 120.2 & 120.2 \\
\hline C18-C19-C14 & 1 & & & & 9.7 & & 119.7 & 119.8 \\
\hline & 109.93 & & & & & 7.7 & 110.3 & 110.6 \\
\hline & & & & & & & & 110.3 \\
\hline C14-P1-C2 & & & & & & & 110.5 & 106.9 \\
\hline & & & & & & & 105.9 & 105.4 \\
\hline C14-P1-C1 & $110.27(11)$ & 110.6 & 110.5 & 110.7 & 110.5 & & 110.4 & 110.5 \\
\hline & & 107.3 & 111 & 110.9 & & 111.1 & 109.6 & 107.7 \\
\hline $\mathrm{C} 1-\mathrm{Br} 1-\mathrm{Br} 2$ & $175.39(7)$ & 179 & 179.1 & 176 & 179.1 & 178.8 & 179.4 & 175.5 \\
\hline
\end{tabular}

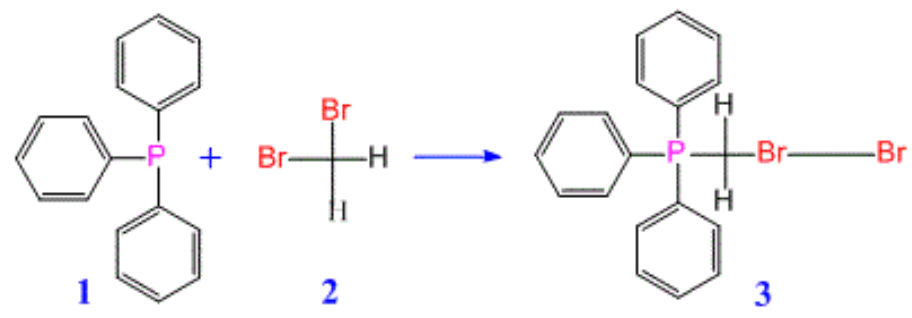

Scheme 1. Synthesis of Bromomethyltriphenylphosphonium bromide

The three dimensional geometrical structure of $\mathbf{3}$ is displayed in Figure $2 \mathrm{a}$ and $\mathrm{b} 2 \mathrm{a}$ represents the experimental $\mathrm{x}$-ray crystal structure with the numbering scheme while $2 \mathrm{~b}$ displays the optimized geometrical structure as predicted by the DFT(B3LYP)/6311+G(d,p) level of theory in the gaseous phase. 


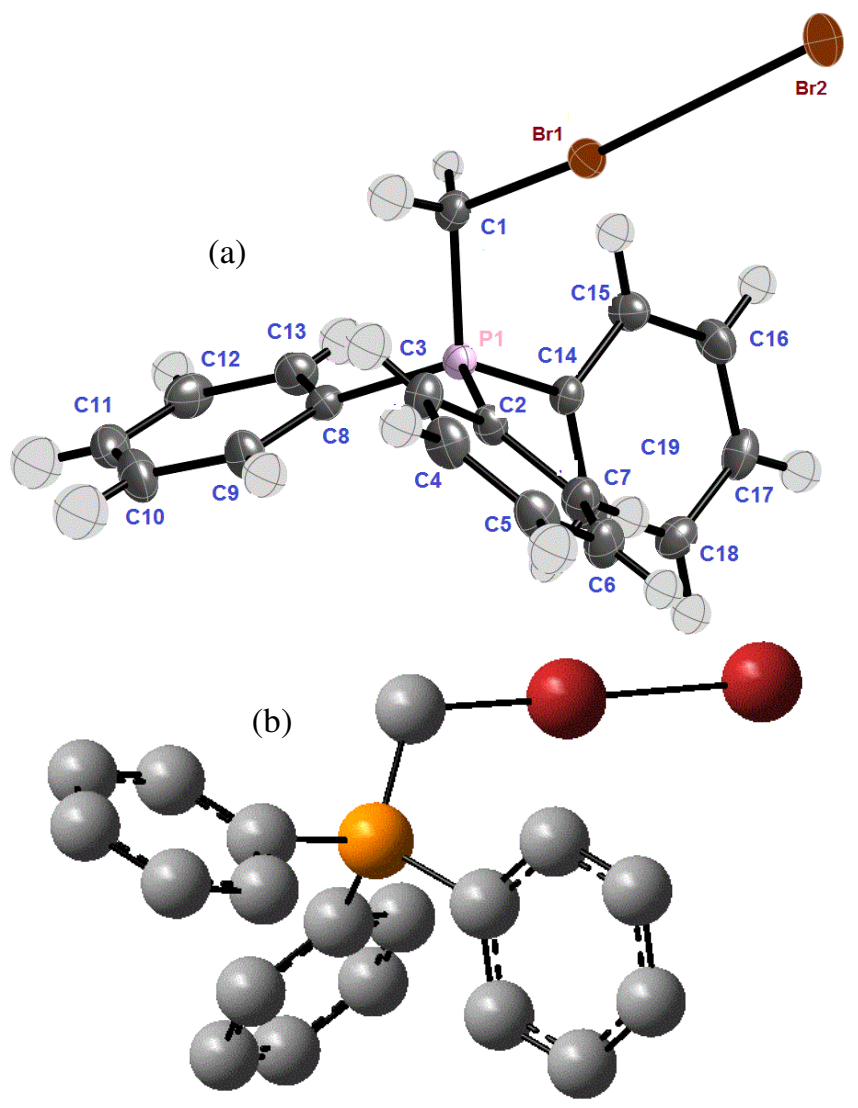

Figure 2. (a) The experimental geometric structure of the title compound at the unit cell with the numbering scheme (b) the theoretical geometrical structure as predicted by B3LYP/6-311+G(d,p) level of theory. Hydrogen atoms were omitted in $1 \mathrm{~b}$ for clarity.

The crystal structure and the theoretical DFT(B3LYP) studies showed that the title compound existed as a solid molecular four-coordinate, tetrahedral geometrical structure, around the phosphorus central atom. The $\mathrm{Br}-\mathrm{Br}$ moiety adopts a co-linear spoke structure, making an experimental angle $175.39(7)^{\circ}$ with the carbon center of the methylene group. The phenyl moieties are in the well known dorsal structure. The $\mathrm{Br}-\mathrm{Br}$ bond 3.597(3) $\AA$ in our compound is considerably lengthened with respect to that in a molecule $\mathrm{Br}_{2}(1.9 \AA)$, but still within bonding distance when compared to the van der Waals radius of $\mathrm{Br}_{2}(4.2 \AA)$ molecule. The extended $\mathrm{Br}-\mathrm{Br}$ bond length in such charge transfer complex is expected, since the LUMO in dibromine is antibonding molecular orbital. Transfer of electron density into this orbital will therefore destabilize the dibromine entity and lead to an increased bond length. Many isoelectronic molecular complexes with long dihalogen or inter halogen bonding interactions have been successfully prepared and studied. The $d_{I-I}$ was found 2.881(2), 2.962(2) and 2.985(2) for $\mathrm{R}_{3} \mathrm{PseI}_{2} ;\left[\mathrm{R}=\mathrm{Ph}, \mathrm{Me}_{2} \mathrm{~N}\right.$, or $\left.\mathrm{Et}_{2} \mathrm{~N}\right]$, respectively ${ }^{1}$. Adducts of the form $\mathrm{R}_{3} \mathrm{PS}-\mathrm{I}-\mathrm{X}$; $\left[\mathrm{R}=\mathrm{Ph}, \mathrm{Me}_{2} \mathrm{~N}\right.$, or $\left.\mathrm{C}_{6} \mathrm{H}_{11}\right]$ with $\mathrm{X}=\mathrm{I}, \mathrm{Br}$ or $\mathrm{CI}$ have been isolated and were crystallography characterized. The X-ray bonding distance, $d_{I-X}$, in $\left(\mathrm{Me}_{2} \mathrm{~N}\right)_{3} \mathrm{PS}-\mathrm{I}-\mathrm{I}$ is 2.856(1) $\AA$. The $d_{I-B r}$ in $\mathrm{Ph}_{3} \mathrm{PS}-\mathrm{I}-\mathrm{Br}$ was found 2.832(6) $\mathrm{A}$, is longer than that of the solid Ibr $(2.52 \AA)^{3}$. 
The predicted DFT(B3LYP) geometrical parameters, viz. bond distances and bending angles in the gas phase within the assigned basis set are in very well agreement with the single $\mathrm{x}$-ray observations of the same parameters. The squared correlation coefficients are 0.903 and 0.991 for the bond distances and bending angles, respectively. The main discrepancies between the gas phase calculations and the observed $\mathrm{x}$-ray crystallography is substantially exist in the $\mathrm{Br}-\mathrm{Br}$ bond distance. The observed $\mathrm{Br}-\mathrm{Br}$ bond length is 359.7(3) pm while the calculated one in the gas phase is $270.8 \mathrm{pm}$. Obviously, the DFT-bases sets employed in gas phase calculations are failed to account very well for the unusual length of the observed $\mathrm{Br}-\mathrm{Br}$ bond distance.

\section{Energy}

Calculations showed that the title compound $\mathbf{3}$ is ground state on the potential energy surface (PFS) whether in the gas phase or in solution due to inexistence of virtual vibrational modes of frequencies. In addition to the molecular tetravalent spoke molecular structure of the title compound, an ionic pair tetravalent geometrical structure has been elucidated in the potential energy surface calculations conducted in the gas phase, Figure 3.

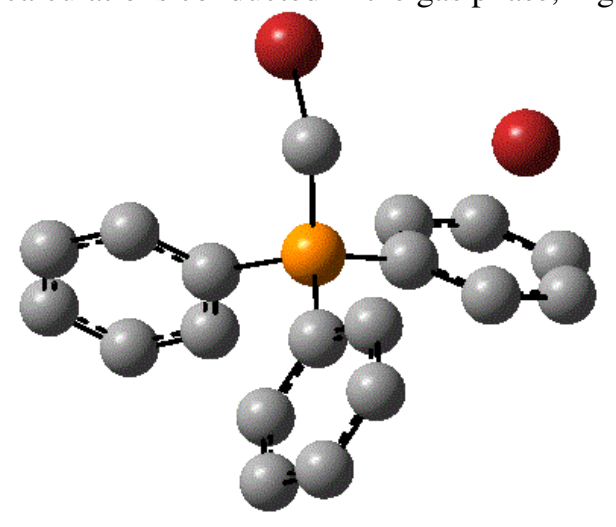

Figure 3. A tetravalent ionic form of bromomethyltriphenylphosphonium bromide as predicted by DFT(B3LYP)/6-311+G(d,p) level of theory. Hydrogens are omitted for clarity

Energy calculations in the gas phase predicted by DFT(B3LYP)/6-311++G(3d,3p)// B3LYP/6-311+g(d,p) showed that the molecular spoke synthesized form is less stable than the di-ionic global ground state form of the title compound by $16.85 \mathrm{Kcalmol}^{-1}$. Calculations conducted at the $\mathrm{R}_{3} \mathrm{PseR}_{2}$ complexes; $\mathrm{R}=\mathrm{H}, \mathrm{Me}, \mathrm{Et}, \mathrm{N}\left(\mathrm{CH}_{3}\right)_{2}, \mathrm{~N}\left(\mathrm{C}_{2} \mathrm{H}_{5}\right)_{2}, \mathrm{Ph}$ or $\mathrm{C}_{6} \mathrm{H}_{11}$, showed that the $\mathrm{T}$-shaped molecular geometries of these complexes are more stable than the molecular spoke ones ${ }^{51}$. Gas phase theoretical investigations on $\mathrm{Ph}_{3} \mathrm{PX}_{2}$ complexes; $\mathrm{X}$ is $\mathrm{Br}$ or $\mathrm{Cl}$, reflected that the charge transfer spoke geometry is the global minima in the case of $\mathrm{X}=\mathrm{Br}$ while it's a local minimum when $\mathrm{X}=\mathrm{Cl}$. The global minimum in the case of $\mathrm{X}=\mathrm{Cl}$ corresponds to the ion pairs tetrahedral geometrical structure.

\section{Solvent effect}

The gas phase predicted wave functions were used as the input wavefunctions in solvent simulations. CPCM model utilizing DFT(B3LYP) functional with the basis set $6-311+\mathrm{g}(\mathrm{d}, \mathrm{p})$ was used in the study for the entire molecules in the presence of the highly polar dielectric dimethylsulfoxide (DMSO) solvent . Extrabasis set (aug-cc-pvqz+d) was used on $\mathrm{P}$ atom. An excellent correlation was found between the observed and the calculated geometrical parameters as it is already shown in Table 2 . Solvent calculations accounts very well for the 
unusual length of the $\mathrm{Br}-\mathrm{Br}$ bond distance $\left(d_{B r-B r}\right)$. The difference in the $\mathrm{Br}-\mathrm{Br}$ bond distance has been eliminated from $86.6 \mathrm{pm}$ in the gas phase to $7.4 \mathrm{pm}$ in DMSO solvent. The study extended to include many solvents, viz., toluene, acetonitrile, dichloromethane and diethylether to investigate the influence of solvent dielectric constant $(\varepsilon)$ on $\mathrm{d} d_{B r-B r}$. Calculations showed that the $d_{B r-B r}$ is fairly well quadratically varied with $\varepsilon$. The variation of $d_{B r-B r}$ with $\varepsilon$ is represented by the relation; $\mathrm{d}_{\mathrm{Br}-\mathrm{Br}}=0.01 \varepsilon^{3}-046 \varepsilon^{2}+12.20 \varepsilon+271.8 ; \mathrm{R}^{2}=0.937$. Deviation from the observed $d_{B r-B r}$ has been remarkably reduced in the presence of solvents with high $\varepsilon$; DMSO and acetonitrile. These results are found in accordance with the average harmonic oscillator index of aromaticity (AHOMA).

AHOMA is calculated using the formula $A H O M A=\frac{1}{N} \sum_{i=1}^{N}\left(1-\frac{\alpha}{n} \sum\left(R_{o p t}-R_{i}\right)^{2}\right)$ where $\mathrm{R}_{\mathrm{i}}$ is the $\mathrm{i}^{\text {th }} \mathrm{C}-\mathrm{C}$ bond distance in the benzene ring within the studied molecule, $\mathrm{R}_{\mathrm{opt}}$ is the optimum C-C bond in benzene (168.8 $\AA$ ), $\alpha=257.7$ is the normalized factor that guarantees that HOMA of aromatic compound approaches 1 and of its Kekul'e nonaromatic structure approaches 0 and $n$ is the number of $\mathrm{C}-\mathrm{C}$ bonds in only one benzene ring ${ }^{52}$. Table 5 displays the AHOMAs and the relative deviations of 3 from unity in the gas phase, in solution in the presence of solvents that aforementioned and x-ray prediction as well. Relative deviations is calculated using the equation: relativedeviation $=\frac{1}{\mathrm{~N}}\left(\sum_{i=1}^{N}\left|\frac{1-A H O M A}{1}\right| X 100\right)$, where $\mathrm{N}$ is the number of benzene rings in the molecular formula of the titled compound.

Table 5. The prediction of AHOMA and the corresponding relative deviation

\begin{tabular}{cccccccc}
\hline Medium & X-Ray & gas & DMSO & $\mathrm{CH}_{2} \mathrm{Cl}_{2}$ & $\left(\mathrm{CH}_{3} \mathrm{CH}\right)_{2} \mathrm{O}$ & Toluene & acetonitrile \\
\hline $\begin{array}{c}\text { HOMA } \\
\begin{array}{l}\text { Relative } \\
\text { deviation }\end{array}\end{array}$ & 0.9859 & 0.9847 & 0.9753 & 0.9752 & 0.9755 & 0.9768 & 0.9751 \\
\hline
\end{tabular}

Calculations showed that the largest value of HOMA is associated with the gas phase calculations where the shortest $d_{B r-B r}$ is noticed. The longest $d_{B r-B r}$ is obtained with DMSO, acetonitrile and dichloromethane, solvents with the highest dielectric constants. Apparently, the calculated AHOMA of the phenyl moieties within our respected complex experienced a slight reduction and thus small relative deviation from unity as it must be for a benzene ring. Reduction of AHOMA of the phenyl moieties in the titled compound could be rationalized in terms of charge transfer of electron density from the $\mathrm{PPh}_{3}$ moiety to the lowest unoccupied untibonding molecular orbital in dibromine. As a consequence of that, the dibromine entity will be destabilized. The $\mathrm{Br}-\mathrm{Br}$ bond order would be reduced, leading to an increase in the $\mathrm{Br}-\mathrm{Br}$ bond distance.

Global hardnesses $\eta$ and global softnesses $\mathrm{S}$ of the molecular form $\mathrm{Ph}_{3} \mathrm{PCH}_{2} \mathrm{Br}-\mathrm{Br}$ and ionic form $\left[\mathrm{Ph}_{3} \mathrm{PCH}_{2} \mathrm{Br}\right]^{+} \mathrm{Br}^{-}$of $\mathrm{Ph}_{3} \mathrm{PCH}_{2} \mathrm{Br}_{2}$ have been expressed in terms of energies of frontier orbitals; the highest occupied molecular orbital (HOMO) and the lowest unoccupied molecular orbital (LUMO), where the global softness is the reciprocal of the global hardness, such that; $\eta=\frac{1}{S}=\frac{\left(E_{L U M O}-E_{\text {HOMO }}\right)}{2}$, where $\mathrm{E}_{\text {НОмо }}$ and $\mathrm{E}_{\mathrm{LUMO}}$ are the energies of the highest occupied and lowest unoccupied molecular orbitals, 
respectively. The calculated $\eta$ and $S$ in the gaseous phase of the molecular spoke and ionic forms in addition to the energies of frontier orbitals in electron volts $(\mathrm{eV})$ are reported in Table 6.

Table 6. Energies of frontier orbitals, global hardness and global softness, all in eV

\begin{tabular}{cccccc}
\hline Structure & $\mathrm{E}_{\text {HOMO }}$ & $\mathrm{E}_{\text {LUMO }}$ & $\eta$ & $\sigma$ & $\chi$ \\
\hline Spoke & -5.1038 & -2.1911 & 2.9127 & 0.3433 & -7.2949 \\
ionic & -4.8809 & -2.2403 & 2.6406 & 0.3787 & -7.1212 \\
\hline
\end{tabular}

The hardness of the spoke form is relatively larger than that of the ionic form while the ionic form is softer than the molecular form. Since softness and hardness can be employed to examine relative reactivity of substances ${ }^{53}$, one would assume that the ionic form is more likely reactive than the spoke one. That's might shed the light on the fact that the di-ionic form has been prepared long time before the spoke one and amazingly employed as it is aforementioned.

\section{Conclusion}

A novel charge transfer tetravalent molecular spoke adduct of the formula $\left(\mathrm{C}_{6} \mathrm{H}_{5}\right)_{3} \mathrm{PCH}_{2} \mathrm{Br}_{2}$ has been prepared and theoretically studied by using DFT(B3LYP) both in gas phase and in solution where CPCM model was employed. Its molecular geometry has been crystallographically identified. Theoretical geometrical parameters were found in very well correlations with the corresponding observed ones in all media involved in the study. Potential surface energy and energy calculations reflected that the theoretical di-ion form of the titled compound is almost more stable in all studied media except in DMSO. The $\mathrm{Br}-\mathrm{Br}$ bond distance has been found quadratically varied with the medium dielectric constant. The average harmonic oscillator index of aromaticity accounted for the remarkable $\mathrm{Br}-\mathrm{Br}$ bond length elongation in terms of charge transfer from the phenyl moieties to the lowest unoccupied anti bonding $\sigma^{*}{ }_{(4 \mathrm{pz})}$ orbital of the $\mathrm{Br}-\mathrm{Br}$ entity. Electronic hardness and softness parameters reflected the possibility of the ionic form to be more reactive than the spoke structure. Besides, the necessity of having diffused functions in phosphorous calculations has been confirmed.

\section{Acknowledgment}

The authors would like to address their gratitude to the Ministry of Education and Higher Education in Gaza for its financial support.

\section{References}

1. Godfrey S M, Jackson S L, McAuliffe C A, and Pritchard R G, J Chem Soc Dalton Trans., 1988, 4201-4204; .DOI:10.1039/A807892K

2. Boyle P D and Godfrey S M, Coord Chem Rev., 2001, 223(1), 265-299; http://dx.doi.org/10.1016/S0010-8545(01)00386-1

3. Cross W I, Godfrey S M, SJackson S L, McAuliffe C A and Pritchard R G, J Chem Soc., Dalton Trans., 1999, 2225-2530; DOI:10.1039/A902433F

4. Boyle P D, Godfrey S M, McAuliffe C A, Pritchard R G and Sheffield J M, Chem Commun., 1999, 2159-2160; DOI:10.1039/A906039A

5. Boyle P D, Cross W I, Godfrey S M, McAuliffe C A, Pritchard R G and Teat S J, $J$ Chem Soc Dalton Trans., 1999, 2845-2852; DOI:10.1039/A903564H

6. Boyle P D, Davidson S E, Godfrey S M and Pritchard R G, Inorganica Chemica Acta., 2001, 325(1-2), 211-214; DOI:10.1016/S0020-1693(01)00635-1 
7. Godfrey S M, Ollerenshaw R T A, Pritchard R G and Richard C L, J Chem Soc Dalton Trans., 2001, 508-509; DOI:10.1039/B100882J

8. Godfrey S M, Jackson S L, McAuliffe C A and Pritchard R G, J Chem Soc Dalton Trans., 1997, 4499-4502; DOI:10.1039/A706180C

9. Barnes N A, Flower K R, Godfrey S M, Hurst P A, Khan R Z and Pritchard R G, Cryst Eng Comm., 2010, 12, 4240-4251; DOI:10.1039/C0CE00024H

10. Bricklebank N, Godfrey S M, Lane H P, McAuliffe C A, Pritchard R G and Moreno J M, J Chem Soc Dalton Trans., 1995, 2421-2424; DOI:10.1039/DT9950002421

11. Schaefer J P and Higgens J, J Org Chem., 1967, 32(5), 1607-1608; DOI:10.1021/jo01280a069

12. Oae S and Togo H, Synthesis, 1981, 371-373; DOI:10.1055/s-1981-29453

13. Cotton F A and Kibala P A, J Am Chem Soc., 1987, 109(11), 3308-3312; DOI:10.1021/ja00245a020

14. Godfrey S M, McAuliffe C A, Prichard R G and Sheffield J M, ChemCommun., 1998, 921-922; DOI:10.1039/A800820E

15. Godfrey S M, McAuliffe C A, Mushtag R I, Prichard R G and Shsffield J M, J Chem Soc., Dalton Trans., 1998, 3815-3818; DOI:10.1039/A807241H

16. Bricklebank N, Godfrey S M, McAuliffe C A and Pritchard R G, J Chem Soc Dalton Trans., 1993, 2261-2266; DOI:10.1039/DT9930002261

17. Godfrey S M, Kelly D G, McAuliffe C A, Mackie A G, Pritchard R G and Watson S M, J Chem Soc Chem Commun., 1991, 1163-1164; DOI:10.1039/C39910001163

18. Bricklebank N, Godfrey S M, Mackie A G, McAuliffe C A, Pritcard R G and Kobryn P J, J Chem Soc Dalton Trans., 1993, 101-103; DOI:10.1039/DT9930000101

19. Bricklebank N, Godfrey S M, Lane H P, McAuliffe C A, Pritchard R G and Moreno J M, J Chem Soc Dalton Trans., 1995, 3873-3879; DOI:10.1039/DT9950003873

20. Wiley G A and Stine W R, Tetrahedron Lett., 1967, 8(24), 2321-2324; DOI:10.1016/S0040-4039(00)90821-9

21. Godfrey S M, McAuliffe C A, Pritchard R G, Sheffield J M and Thompson G M, J Chem Soc Dalton Trans., 1997, 4823-4828; DOI:10.1039/A705201D

22. Bricklebank N, Godfrey S M, Mackie A G, McAuliffe C A and Pritchard R G, J Chem Soc Chem Coummun., 1992, 355-356; DOI:10.1039/C39920000355

23. Godfrey S M, McAuliffe C A, Pritchard R G and Sheffield J M, Chem Commun., 1996, 2521-2522; DOI:10.1039/CC9960002521

24. Cross W I, Godfrey S M, McAuliffe C A, Pritchard R G, Sheffield J M and Thompson G M, J Chem Soc Dalton Trans., 1999, 2795-2798; DOI:10.1039/A903974K

25. Beveridge A D, Harris G S, and Payne D S, J Chem Soc (A), 1966, 726-727; DOI:10.1039/J19660000726

26. Mont W W, Batcher M, Pohl S and Saak W, Angew Chem Int Ed Engl., 1987, 26(9), 912-913; DOI:10.1002/anie.198709121

27. Burgess K M N, Korobkov I and Bryce D L, Chem Eur J., 2012, 18(18), 5748-57585; DOI:10.1002/chem.201103478

28. Wolinsky $\mathrm{J}$ and Erickson K L, J Org Chem., 1965, 30(7), 2208-2211; DOI:10.1021/jo01018a021

29. Vogt H, Lauritsen K, Riesel L, von Loewis M and Reck G, Zeitschrift fuer Naturforschung B: Chem Sci., 1993, 48(12), 1760-1766; DOI:10.1515/znb-1993-1211

30. Du Z and Erickson K L, J Org Chem., 2010, 75(21), 7129-7140; DOI:10.1021/jo101222v 
31. Vogt H, Lauritsen K, Riesel L, von Löwis M and Reck G, Z Naturforsch, 1993, 48b, 1760-1766.

32. Bruker. SMART (Version 5.630) and SAINT-Plus (Version 6.45A). Bruker AXS Inc., Madison, Wisconsin, USA, 2003.

33. Sheldrick G M, Acta Cryst., 2008, A64, 112-122; DOI:10.1107/S0108767307043930

34. Becke A D, J Chem Phys., 1993, 98(7), 5648-5652; DOI:10.1063/1.464913

35. Lee C, Yang $\mathrm{W}$ and Parr R G, Phys Rev B, 1988, 37(2), 785-789; DOI:10.1103/PhysRevB.37.785

36. Dunning Jr T H, Peterson K A and Wilson A K, J Chem Phys., 2001, 114, 92449253; DOI:10.1063/1.1367373

37. Martin J M L, Spectrochemica Acta A Molecular Biomolecular Spectroscopy, 1999, 55(3), 709-718; DOI:10.1016/S1386-1425(98)00271-6

38. Martin J M L, Chem Phys Lett., 1999, 310(3-4), 271-276; DOI:10.1016/S00092614(99)00749-6

39. Mkadmh A M, Chem Sci Trans., 2013, 2(3), 781-796; DOI:10.7598/cst2013.515

40. Barone V, Cossi M and Tomasi J, J Comput Chem., 1998, 19(4), 404-417; DOI:10.1002/(SICI)1096-987X(199803)19:4<404::AID-JCC3>3.0.CO;2-W

41. Cossi M, Rega N, Scalmani G and Barone V, J Comp Chem., 2003, 24(6), 669-81; DOI:10.1002/jcc.10189

42. Garvey J F, Herron W J and Vaidyanathan G, Chem Rev., 1994, 94(7), 1999-2014; DOI:10.1021/cr00031a011

43. Cossi M, Barone V, Mennucci B and Tomasi J, Chem Phys Lett., 1998, 286(3-4), 253-260; DOI:10.1016/S0009-2614(98)00106-7

44. Cossi M, Barone V, Cammi R and Tomasi J, Chem Phys Lett., 1996, 255(4-6), $327-$ 335; DOI:10.1016/0009-2614(96)00349-1

45. Cances M T, Mennucci V and Tomasi J, J Chem Phys., 1997, 107, 3032-3041; DOI:10.1063/1.474659

46. Barone V, Cossi M, Mennucci B and Tomasi J, J Chem Phys., 1997, 107, 32103221; DOI:10.1063/1.474671

47. Frisch M J, Gaussian 09, Revision A.02; Gaussian, Inc., Wallingford CT, 2009.

48. Frisch A, Nielsen A B, Holder A, 2000. Gaussview Users Manual, Gaussian Inc.

49. http://www.chemcraftprog.com

50. Macrae C F, Edgington P R, McCabe P, Pidcock E, Shields G P, Taylor R, Towler M and van de Streek J, J Appl Cryst., 2006, 39, 453-457; DOI:10.1107/S002188980600731X

51. Mkadmh A M, Hinchliffe A and Abu Awwad M F, J Mol Struct Theochem, 2008, 719(1-3), 87-93; DOI:10.1016/j.theochem.2005.01.027

52. Ostrowski S, and Dobrowolski J C, RSC Adv., 2014, 4, 44158-44161; DOI:10.1039/C4RA06652A

53. Roy R K, Krishnamurti S, Geerlings $\mathrm{P}$ and Pal S, J Phys Chem A, 1998, 102(21), 3746-3755; DOI:10.1021/jp973450v 